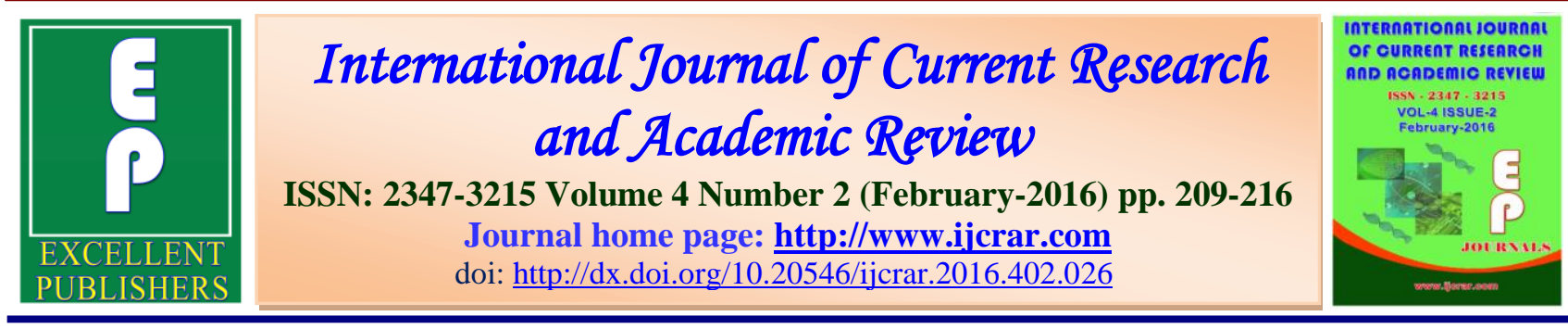

\title{
Opinion towards Hybrid Learning among teacher educators at Perambalur District, India
}

\author{
K. Santha Kumari* \\ Dhanalakshmi Srinivasan College of Education, Perambalur, India \\ *Corresponding author
}

KEYWORDS

Hybrid Learning,

Teacher educators, Information

Technology (IT)

\section{A B S T R A C T}

The rapid advancement in information technology (IT) has made remarkable changes in the traditional educational systems. It adopts modern technology and pedagogical techniques in teaching-learning process and creates a learning environment that motivates the students for better learning. Blended learning (BL) or hybrid learning describes a learning environment that either combines teaching methods, delivery methods, media formats or a mixture of all these. It also refers to the integrated learning activities such as a mixture of online and face-to-face learning. In other words, BL is a mixture of e-learning and traditional types of learning. It is mentioned as the integrated combination of traditional learning with web-based online approaches, the combination of media and tools deployed in an e-learning environment and the combination of a number of pedagogical approaches. Among the benefits of BL reported by recent research were (i) provide students with more control over learning; (ii) help foster critical thinking; (iii) effectiveness of online assessment system and computer tutorials.

\section{Introduction}

The rapid advancement in information technology (IT) has made remarkable changes in the traditional educational systems. It adopts modern technology and pedagogical techniques in teaching-learning process and creates a learning environment that motivates the students for better learning. Such a system of learning is mainly based on internet services which facilitate active learning. It disseminates different types of information needed for the holistic development of an individual. Blended learning has emerged as an effective method of learning to meet the needs of students' learning style. The growth of blended learning environments in education has emphasized the need for better ways of describing and recognizing good teaching that promotes students learning in this environment. Blended learning combines online components with the conventional face-to-face components that 
optimize best practices in teaching and learning through synchronous and asynchronous learning environments.

\section{Blended Learning or Hybrid Learning}

Blended/ Hybrid Learning is a term increasingly used to describe the way elearningis being combined with traditional classroom methods and independent study to create a new, hybrid teachingmethodology .It represents a much greater change in basic technique than simply adding computers to classrooms; it represents, in many cases, a fundamental change in the way of teachers and students approach in learning experience. It has already produced an offshoot - the flipped classroom - that has quickly become a distinct approach of its shown.

Blended learning (BL) or hybrid learning describes a learning environment that either combines teaching methods, delivery methods, media formats or a mixture of all these. It also refers to the integrated learning activities such as a mixture of online and face-to-face learning. In other words, BL is a mixture of e-learning and traditional types of learning. It is mentioned as the integrated combination of traditional learning with web-based online approaches, the combination of media and tools deployed in an e-learning environment and the combination of a number of pedagogical approaches. Among the benefits of BL reported by recent research were (i) provide students with more control over learning; (ii) help foster critical thinking; (iii) effectiveness of online assessment system and computer tutorials.

\section{Association between U-Learning and $\mathrm{H}$ - Learning}

It is clear that hybrid learning is a mixture of online and face-to-face learning using a variety of learning resources and communications options available to students and lecturers. In other words, hybrid learning mixes u-learning with traditional type (T-learning: Classroombased) of learning.

Traditional learning (T-Learning) type is classroom-based and offers the learner faceto-face contact and support, in which the major learning modes are instructor-led and group-based. Ubiquitous learning (ULearning), which can be delivered anywhere, anytime through mobile and handheld devices, provides the online program or resources for learners, in which the main leaning modes are self-paced and peer-to-peer. Of course, ubiquitous learning also has the affects that learners may feel isolated that sometimes may affect motivation and student retention. Hybrid learning offers some of the best of both worlds: face-to-face tutor support and contact with peers through the ability of online mobile communication. By practicing hybrid the conveniences of online courses and mobile learning are gained without the loss of face-to-face contact. So a learning environment is created that is richer than either a traditional face-to-face environment or a fully online environment. However, it is important to establish the equilibrium between face-to-face education and online mobile environments during the process of organizing hybrid learning environments.

\section{Principles of Hybrid Learning/ Blended Learning}

The following seven pedagogical goals for constructivist hybrid learning environments

\section{Provide experience with the knowledge construction process}

Students created rather than used a multimedia learning environment. They were supposed to collect information from a 
variety of sources. Relevant information had to be selected, analyzed and related to their individual prior knowledge. This had then to be structured and edited in accordance with the demands of a web-based learning environment.

\section{Provide experience in appreciation for multiple perspectives}

As students had to acquire declarative knowledge and prepare and edit learning material, they experienced being both in the roles of learners and instructional designers. Furthermore, the media created had to be presented and evaluated in class.

\section{Embed learning in realistic and relevant contexts}

The course dealt with realistic and authentic situations for psychology and education students. Not only did they write a theoretical learning text for the web-based learning environment, they also had to come forward with practical examples and exercises for their particular topic. The applied principles of instructional design were especially relevant for their future work in schools and other educational institutions.

\section{Encourage ownership and voice in the} learning process

All participants of the course took responsibility for the project. Personal contributions had to be presented and defended in class. Thus, the degree of individual achievement was made apparent in the course of production and at the end, when the learning environment was put online.

\section{Embed learning in social experience}

The project was planned, run, evaluated and modified within an active dialogue in class as well as in small working groups. Aspects concerning the entity of the web-based learning environment (e.g., the structure and layout of the learning environment) were negotiated in class.

\section{Encourage the use of multiple modes of representation}

Students had to design various learning media: learning texts, different modes of exercises including informative feedback, practical examples, slides, as well as commented links to Internet resources. The specific demands that arise from the particular character of a certain medium had to be recognized.

Encourage self-awareness in the knowledge construction process

The process of creating a web-based learning environment was articulated and reflected during the complete period of course. This included continuously working on the personal contributions in small working groups and continuously evaluating the contributions already presented in class. Results of the class' evaluations were used to revise the presented contributions.

We expected that pursuing these goals in a hybrid learning course would enable students to engage in active, mindful and purposeful knowledge acquisition and reflection as well as in the development of critical thinking skills.

\section{Difficulties to Blended Learning/ Hybrid Learning}

Despite the advantages, there are some difficulties with blended learning. These can be reduced or overcome. To avoid these points might reduce the quality of teaching in this mode. These might include: 
Bias:Some people have difficulty using or accepting teaching methods that are unfamiliar or unconventional. In the case of computer mediated learning, some people cannot use computers well or prefer to avoid using them. Blended learning can be adapted to suit not only the learners but also the teachers.

Faculty difficulties: Faculty compensation and initial difficulties to cope up with the learning requirement to teach in this mode. Not all instructors are as effective in teaching blended courses.

Lack of means: One may not have enough time, money, equipment, etc. E-learning classes cannot function if instructors and students cannot operate the necessary hardware and software. Some schools may not have enough computer rooms for every teacher to use one, a school may not even have computers at all, or a teacher may not have the time or skills to create computer activities for lessons. Lack of time to train on various technological tools.

Poor mixes: Learning methods and tools need to be used well in conjunction with each other. Careful thought needs to go into making a good blend.

Computer difficulties: Students might have different computers with different bandwidth capabilities. Different speed of computers used by the students.

\section{Objectives of the Study}

To measure the level opinion towards blended hybrid /learning among teacher educators at perambalur district. To find out the significant difference between the mean values of opinion towards blended hybrid/ learning among teacher educators on the basis of their gender, locality of the college, age, stream of study, experience.

\section{Hypotheses of the Study}

The level of opinion towards blended hybrid/learning among the teacher educators at Perambalur district.

There is no significant difference between the opinion towards blended hybrid / learning among the teacher educators on the basis of their gender, locality of the college, age, stream of study, experience.

\section{Need and Significance of the Study}

Most of the traditional class room teachinglearning process fails to engage the young learners actively to construct the knowledge. The knowledge is transferred monotonously and their needs, interests and attitude have never taken into account.

With the advancement of technology, it is possible to revolutionize the way people learn and to present the information to them. Most of the traditional instruction, students learn from the instructor-led approach. Usually in a traditional classroom setting, students have access to the experts, involved in questions and discussion, exposed to social interaction and have the opportunity to learn from others. Some students prefer an individualized or less structured environment. In other words, they need selfpaced learning material. At the same time, educators are now facing with the challenges of integrating traditional and emerging technology as to balance various students learning styles.

Teachers experience difficulties in teaching their students since they have to understand the interest and mood of the students. In certain cases, they need to visualize the 
picture when applying some hard subject matters. Studies have shown that attitude to be one of other reasons why teaching in traditional method is so difficult. Most of these experimental methods of teaching have not shown that traditional methods can affect students' attitude towards learning various subjects. It also mentioned that technological aids such as computers have improvement effects on students' attitudes towards education. With the help of the technology, blended learning (BL) makes it easy for students to study and be able to change their attitude towards education.

\section{Method Adopted in the Present Study}

In the present study, the investigator has employed the 'survey method'.

\section{Sample and Sampling Technique}

The investigator was selected 102 teacher educators for the present study. The present study is adopted with the Random Sampling Technique.

\section{Tool Used for the Study}

Tool used in order to collect the necessary data to achieve the objective of the study "Opinion towards Blended/Hybridlearning among teacher educators" developed by the investigator.

\section{Scoring Procedure}

The tool used to investigate the opinion towards blended/hybrid learning among teacher educators consist of 50 questions which is constructed in four points. The values given for the positive and negative questions are given below:Positive score: 4,3,2,1Negative score: 1,2,3,4

\section{Reliability of the Tool}

To find out the reliability of the tool, split half methodwas used. The reliability of the test has been calculated by using Person's product-moment correlation coefficient formula. The value obtained was 0.83 .

\section{Statistical Techniques Used}

Statistical techniques serve the fundamental purpose of the description and inferential analysis. The data was collected from various colleges .Investigator developed the Master table and the data has been analyzed by using appropriate statistical techniques, such as Mean, SD, t test, f test

Table.1 Mean and Standard Deviation Scores on the Level of Opinion Towards Blended/Hybrid Learning among Teacher Educators At Perambalur District in Total

\begin{tabular}{|c|c|c|c|c|c|}
\hline S. No & \multicolumn{2}{|c|}{ Variables } & $\mathbf{N}$ & Mean & SD \\
\hline & \multicolumn{2}{|l|}{ Total } & 102 & 82.96 & 8.14 \\
\hline \multirow[t]{2}{*}{01} & \multirow[t]{2}{*}{ Gender } & Female & 51 & 82.05 & 8.43 \\
\hline & & Male & 51 & 83.87 & 7.80 \\
\hline \multirow[t]{2}{*}{02} & \multirow[t]{2}{*}{ Locality of the College } & Rural & 44 & 85.32 & 6.98 \\
\hline & & Urban & 58 & 81.17 & 8.54 \\
\hline \multirow[t]{2}{*}{03} & \multirow[t]{2}{*}{ Age } & Below30 & 31 & 81.32 & 8.84 \\
\hline & & Above 30 & 71 & 83.68 & 7.77 \\
\hline \multirow[t]{2}{*}{04} & \multirow[t]{2}{*}{ Stream of Study } & Arts & 49 & 82.64 & 7.65 \\
\hline & & Science & 53 & 83.25 & 8.62 \\
\hline \multirow[t]{2}{*}{05} & \multirow[t]{2}{*}{ Experience } & Below 5 years & 51 & 81.66 & 8.47 \\
\hline & & Above 5 years & 51 & 84.26 & 7.65 \\
\hline
\end{tabular}


Int.J.Curr.Res.Aca.Rev.2016; 4(2): 209-216

Table. 2 t' Value Between the Mean Scores on the Level of Opinion Towards Blended/Hybridlearning among Teacher Educators with Respect to their Different Variables

\begin{tabular}{|l|l|l|l|l|l|}
\hline S.No & Variables & N & Mean & SD & 't'value \\
\hline 01. & Male & 51 & 83.87 & 7.80 & \\
& female & 51 & 82.05 & 8.43 & 1.13 \\
\hline 02. & Rural & 44 & 85.32 & 6.98 & \\
& urban & 58 & 81.17 & 8.54 & 2.69 \\
\hline 03. & Below 30 & 31 & 81.32 & 8.84 & \\
& Above 30 & 71 & 83.68 & 7.77 & 2.28 \\
\hline 04. & Arts & 49 & 82.64 & 7.65 & \\
& science & 53 & 83.25 & 8.62 & 0.37 \\
\hline 05. & Below 5 years & 51 & 81.66 & 8.47 & \\
& Above 5 years & 51 & 84.26 & 84.26 & 1.63 \\
& & & & & \\
\hline
\end{tabular}

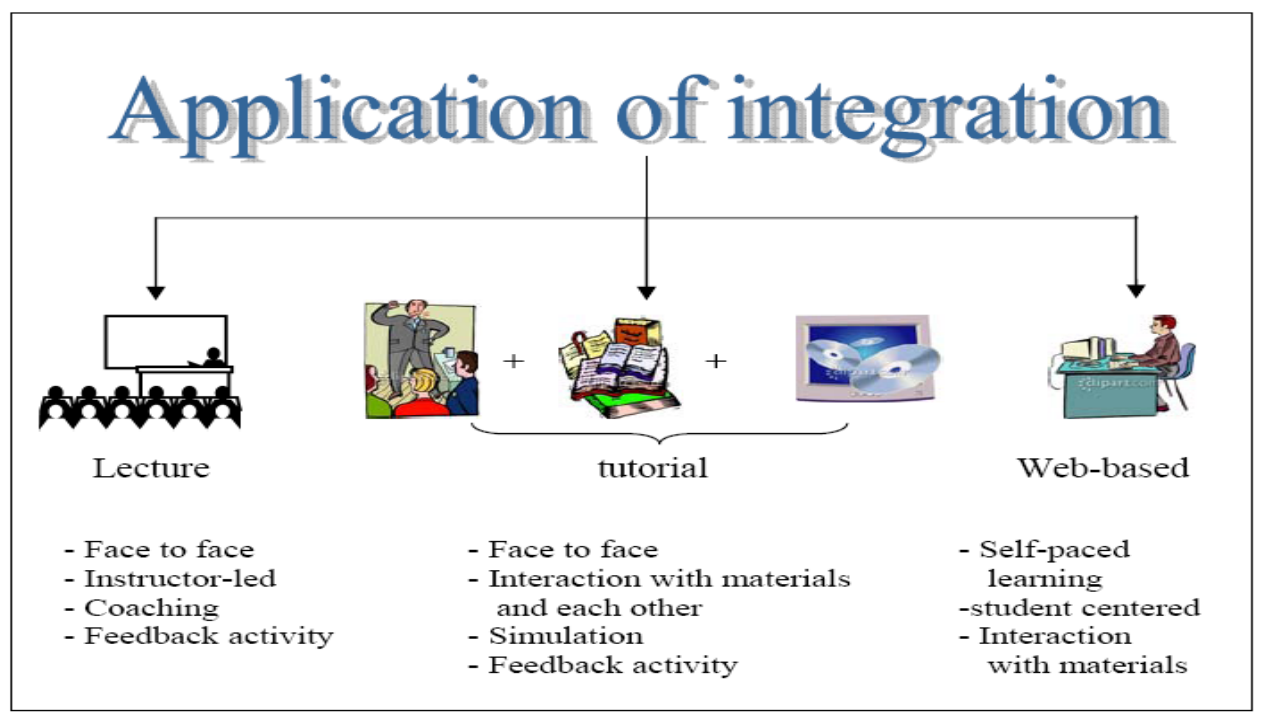

Figure.2 Description of H-Learning

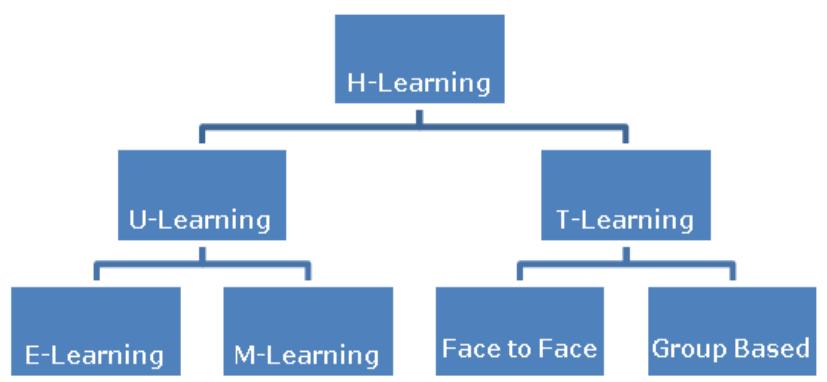




\section{Hypothesis - 1}

The level of Opinion towards Blended /hybrid Learning among Teacher Educators at Perambalur District

It is clearly seen from the Table 4.1 the obtained Maximum and Minimum Mean and SD values of the Opinion towards Blended /hybrid LearningScores are 85.32 and 78.94 and 9.21 and 6.98. It is also reveal that Mean and SD of the Opinion towards Blended /hybrid LearningScore of the total sample were 82.96 and 8.14(Maximum value is 200 and the minimum value is 50 ). It shows that the level of Opinion towards Blended/hybrid learning among Teacher Educators is high.

\section{Hypothesis - 2}

There is no significant difference between the opinions towards blended/hybrid learning among the teacher educators on the basis of their gender, locality of the college, age, stream of study, experience

From the above Table 4.2 it is seen that the ' $t$ ' value, is not significant at 0.05 level. It is understood from the result that there is no significant difference in the level of Opinion towards Blended/hybrid Learning among Teacher Educators with respect to their Gender steam of study and experience. And there is a significant at 0.05 levels. It is understood from the result that there is significant difference in the level of Opinion towards Blended/hybrid Learning among Teacher Educators with respect to their locality of the college and age.

\section{Findings of the Study}

Opinion towards blended/ hybrid learning among teacher educators is high.
There is no significant difference in the level of opinion towards blended/hybrid learning among teacher educators with respect to their gender, locality of the college, age, stream of study, marital status, experience, income.

\section{Educational Implications}

Enhance the Blended/hybrid Learning classes in teacher education and make it compulsory for irrespective of the optional subjects.

The usage of Internet facilities should be increased for the student teachers, to improve the level of blended/hybrid learning.

In-Service training programs may include cultivating an effective attitude towards the Blended Learning/hybrid .

Innovations in Blended/hybrid Learning should be encouraged by the Government sector at different level of education.

State level study can be taken for further research.

\section{Conclusion}

The concept of blended/hybrid learning has been with us for some time and really builds on the good practice of blending teaching and learning styles for the benefit of the learner.. The potential of new technologies can be maximized when you see how best to blend e-learning with existing program to the benefit of learners. The results provide evidence that the opinion towards hybrid Learning among teacher educators is high. It should implement in the teacher education colleges so that the students and teacher educators would get more knowledge through internet, multimedia and other 
teaching aids in order to get clarity about the conceptual learning.

\section{References}

Amit Kauts and Gurkiran Kaur Blended Learning : A shift from Unimodal to Multimodal, university News,52(9) 2014

Augustus Richard. J and Muthaiah. NCan Blended Learning enhance Teaching Skills? 2012
Bonk. C.J. \& Graham.C.RHand Book of Blended Learning, Global Perspective, local designs. San Francisco: Pfeiffer Publishing 2004.

Pape, Liz Blended Teaching \&Learning, Education Digest: Essential Readings condensed for Quick Review. V76 (2010).

\section{How to cite this article:}

Santha Kumari, K., 2016. Opinion towards Hybrid Learning among teacher educators at Perambalur District, India. Int.J.Curr.Res.Aca.Rev. 2016.4(2): 209-216. doi: http://dx.doi.org/10.20546/ijcrar.2016.402.026 